
E UM ESTUDO DE CASO

\title{
MUNICIPAL BASIC SANITATION PLANNING: A METHODOLOGY OF SUPPORT FOR LOCAL PUBLIC MANAGEMENT AND A CASE
}

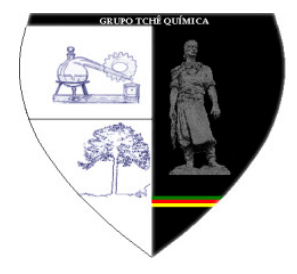

\author{
RODRIGUES, Adriana Brandt1; GROENWOLD, Janine Alícia²; DIAS, Renata Saviato*; \\ BENASSI, Simone Frederigi ${ }^{4}$
}

\footnotetext{
${ }^{1,3}$ Fundação Parque Tecnológico Itaipu, Programa Desenvolvimento Econômico e Social Sustentável da Região Oeste do Paraná - Projeto Saneamento Ambiental, Av. Tancredo Neves, 6731, CEP 85867-900, Foz do Iguaçu - PR, Brasil
}

(fone: +55 45 3576-7200 ; fax: +55 45 3576-7199)

${ }^{2,4}$ ITAIPU Binacional, Diretoria de Coordenação, Divisão de Reservatório e Divisão de Serviços, Av.

Tancredo Neves, 6731, CEP 85867-900, Foz do Iguaçu - PR, Brasil

(Fone: +55 45 3520-5252)

${ }^{*}$ Renata Saviato Dias

e-mail: renata.dias@pti.org.br

Received 09 October 2017; received in revised form 19 November 2017; accepted 20 December 2017

\section{RESUMO}

A Fundação Parque Tecnológico Itaipu em parceria com a Itaipu Binacional desenvolve ações no oeste do Paraná para promoção de um diálogo regional sobre saneamento básico e sua relevância na saúde pública. Para tanto, foi desenvolvida uma metodologia de apoio técnico moldada às Prefeituras desta região para elaboração ou revisão dos Planos de Saneamento Básico e de Resíduos Sólidos. Conforme a Política Nacional de Saneamento Básico (Lei Federal n.⒒445/2007), os municípios devem planificar seus serviços públicos de saneamento básico nos quatro eixos e, neste contexto, foram definidos os processos que definem a metodologia de apoio, como: assistência para pleno cumprimento da Lei e priorização do diálogo social; apoio técnico para diagnóstico e formulação de metas e projetos; e instituição das Políticas Municipais. A partir do caso de Pato Bragado/PR constatou-se a conveniência e a eficácia do incentivo à Prefeitura para preconização do tema, além da efetivação da mobilização social e a conscientização da gestão municipal como pontos chaves para o impulso às ações saneadoras. Por ser provido e zelado pela Administração Pública, o planejamento é indelegável a essa, contudo a intervenção técnica apresenta-se viável para reforço do dever, fortalecimento técnico do planejamento e garantia de cumprimento legal.

Palavras-chave: Política pública, municípios, planejamento, saneamento básico.

\section{ABSTRACT}

The Itaipu Technological Park Foundation in partnership with Itaipu Binacional develops actions in the western Paraná / Brazil purposing the promotion of a regional dialogue on basic sanitation and its relevance on health. Therefore, a methodology of technical support to public management was developed for Basic Sanitation and Solid Waste Plans, in consonance with the counties reality and contributing to universal access to sanitation services and legal compliance. According to the BrazilianPolicy on Basic Sanitation (Federal Law 11455/2007), municipalities should plan their public services in the four axes, and in this context, the processes that define the support methodology we redefined, such as: assistance to prioritization of the social dialogue; technical support for diagnosis and formulation of goals and projects; and institution of the Municipal Policies. This study presents the methodology applied in Pato Bragado/PR, where 
the motivation of the county's technicians was observed, as well as the effectiveness of social mobilization and the awareness of municipal management as key points for boosting sanitation actions. Since it is provided and supervisedby the Public Administration, basic sanitation planning is not delegable. However, the possibility of intervention presented as a viable alternative for reinforcement of the duty, technicalstrengthening of the planning, and guaranteeof legal compliance, presenting greatreturn.

Keywords: Public policy, counties, planning, basic sanitation.

\section{INTRODUÇÃO}

A expressão saúde ambiental assumiu, atualmente, um papel de sensibilização de atores chaves e orientação de uma gestão articulada entre a saúde e bem-estar humano e o meio ambiente, seu influente direto ( $\mathrm{LAHOZ}$ E DUARTE, 2015). De acordo com Heller (1998), obtém-se com esta aproximação uma conscientização onde o ambiente é valorizado e preservado e compreende-se qual sua relação sobre a saúde humana.

Ao longo da história e em diversas civilizações, detecta-se a constatação da relação entre a saúde humana e o saneamento como meio para prevenção de doenças (SERILO et al., 2014). Estas proposições asseguram a necessidade de sanear o meio, compreendendo seus impasses e consequências, considerando o âmbito social e econômico, além da questão de zoneamentos e fatores de risco agregados. Menezes já em 1984 definiu em seu trabalho que esta ação compete ao saneamento ambiental, diferente do saneamento básico que se apresenta como um eixo mais restritivo, abordando somente ações de saúde pública em abastecimento de água, esgotamento sanitário, coleta e manejo de resíduos sólidos e drenagem de águas pluviais visando o controle de vetores e patógenos.

Contudo, apresar desta estreita relação, é visível a ausência de atenção neste setor, retratada por dados fornecidos pelo Instituto Brasileiro de Geografia e Estatística - IBGE (2010) os quais indicam que apenas $44 \%$ das residências possuem esgotamento sanitário e que deste montante coletado, somente $68,8 \%$ tem devido tratamento. Demolier (2008) cita que a referida e demonstrada negligência é devido a um nexo com popularidade dos gestores públicos que optam por obras mais apreciadas por eleitores que, no entanto, nos as beneficiam no quesito de serviços e direitos fundamentais. Lahoz e Duarte (2015) citam que para a preservação da saúde, é fundamental o serviço público de saneamento cujas ações minimização prejuízos ao bem-estar da população e afirmam que a instauração da saúde plena tão só será viabilizada quando o direto fundamental de serviços públicos de saneamento básico for alcançado.

Igualmente, Escoda (2005) menciona que o saneamento básico é considerado um tema irrelevante no contexto custo-benefício impacto, sendo este último eixo referente ao impacto superfulo incidido na população. Isto porque é distante a definição, a importância e as consequências positivas do saneamento à sociedade cuja noção invisibiliza e desaprecia as ações de saneamento. Esta insipiência é uma das razões que desvirtua 0 desenvolvimento de políticas públicas nos órgãos públicos. Quintas (2005) explica bem esta percepção mencionando que na atuação com sociedades civis, observam-se em casos omissões, incapacidades, incompreensões e desinteresse da população e ainda a conivência dos órgãos públicos, ou seja, um ciclo. Contudo, é de dever da gestão pública iniciar, incentivar e incrementar ações conjuntas de gestão ambiental e políticas.

Visando então desenvolver este eixo e aplicá-lo a todo território nacional, a esfera governamental iniciou uma articulação legal e financeira para que o Brasil alcance metas de atendimento mínimo da qualidade da água e saúde pública, garantindo assim sua sustentabilidade. Para tanto, foram instituídas legislações que regem os setores afins as causas, sendo a Lei $n^{\circ} 11.445$ de 2007 que apresenta diretrizes nacionais para 0 saneamento básico a principal delas. Contudo, 
Leoneti, Prado e Oliveira (2001) aponta que apesar do propósito de sustentabilidade da legislação, esta apresenta termos preventivistas e ainda não traz, claramente, as atribuições das esferas governamentais ocasionando trabalhos replicados ou negligência (QUINTAS, 2005).

Então, foi a partir do Século XXI que a União proporcionou força ao tema saneamento retomando programas de financiamento e, em sua primeira década, instituindo importantes instrumentos jurídicos de interesse, sendo tais: Lei Federal n.. 10.257/2001 - Estatuto da Cidade; Lei Federal n. $\stackrel{\circ}{11.107 / 2005}$ Contratação de consórcios públicos; Lei $\mathrm{n} .{ }^{\circ}$ 11.445/2007 - Política Nacional de Saneamento Básico; Resolução Recomendada n. 62 - Pacto Nacional de Saneamento Básico para elaboração do Plano Nacional de Saneamento Básico - PLANSAB; Lei Federal n. ${ }^{\circ}$ 12.305/2010 - Política Nacional de Resíduos Sólidos; dentre outras.

A aprovação da Lei Federal n. 011.445 de 2007 deu-se necessária visto a imprescindibilidade de fixação de diretrizes gerais sobre o ordenamento do saneamento básico e distinção dos modelos de organização institucional legal dos serviços de abastecimento de água, esgotamento sanitário, drenagem urbana e manejo resíduos sólidos e limpeza urbana. Juntamente ao seu Decreto Federal Regulamentador n. 07.217 de 2010, menciona que os serviços devem ser sustentáveis economicamente, apresentar função social e impõem o prazo máximo de quatro anos para a revisão dos planejamentos municipais. Em seu cerne, a Política Nacional de Saneamento Básico apresenta quesitos como universalização dos serviços, promoção da saúde pública, compreensão das peculiaridades locais, articulação com outras políticas e, com relevância, designa o Poder Público Municipal como titular pelas ações de planejamento e responsável pela prestação, regularização e fiscalização dos serviços.

A Política expressa também a obrigatoriedade de elaboração dos Planos Municipais de Saneamento Básico (PMSB) a todos os municípios brasileiros com prazo final, segundo o Decreto no 8.629 de 2015, até dezembro de 2017 e, após esta data, aqueles que não o instituírem estarão impedidos de acessar recursos federais para tal fim. Motivase este prazo em razão de serem, além de instrumentos para planejamento, também mecanismos pelos quais é possível a mensuração qualiquantitativa de desempenho dos serviços prestados seja no quesito técnico, econômico ou financeiro. Junior, Sobrinho e Sampaio (2010) sustentam que a desobediência à Lei pode ocasionar invalidez de contratos de objeto saneamento, restrição de acesso aos recursos públicos, entre outras ríspidas consequências. Da mesma maneira, as metas elencadas nos planos devem ser exequíveis operacional e financeiramente.

Para estarem aptos à solicitação de recursos, os PMSB também devem ser aprovados pela sua instância de elaboração, sejam Comitês ou Comissões Municipais, em uma Conferência Pública e via Poder Legislativo na Câmara de Vereadores. Esta instância sanciona os planejamentos via Lei ou Decreto, tornando-os Políticas Públicas Municipais de Saneamento. Além disso, ao compararmos ao recomendado por Braga (1995) para Planos Diretores, pode-se considerar que um plano será bem-sucedido caso seja coordenado pela própria municipalidade, visto ser o órgão que conhece a totalidade das necessidades de seu território e, desta forma, atenda plenamente a esse. Ainda segundo o autor, deve-se garantir a participação efetiva da sociedade, através de representatividades ou outras formas, a fim de multiplicar e diversificar a discussão da política pública municipal, além do fundamental interesse legítimo da administração municipal na elaboração destes planejamentos, compreendendo-os como ferramentas de atuação territorial, otimização de recursos e desenvolvimento; e não somente como uma imposição legal ou modismo.

Os serviços públicos de saneamento básico possuem abrangência municipal e, desta forma, são de interesse local. Em concordância então ao Artigo 30 da Constituição Federal que estabelece ser de competência municipal assuntos de interesse local, o planejamento, a organização, a prestação, a regulação e a fiscalização dos serviços de saneamento básico são de responsabilidade das Administrações Municipais. Contudo, a Constituição não 
permite inferir explicitamente a titularidade destas ações e então, com 0 intuito de esclarecer e fixar tais competências, a Política Nacional de Saneamento em seus Artigos $8^{\circ}$ e 9 evidencia a impossibilidade de delegação do planejamento, tornando a Gestão Local responsável pelos PMSB e em consonância ao seu Decreto Regulamentador n. 0 7.217/2010 artigo 23 que incumbe o titular dos serviços pela formulação da política pública de saneamento básico. Isto por que é a única que pode zelar integralmente pelo bem público e ademais ser o planejamento o norteador de todas as ações de gestão: organização, prestação, regulação e fiscalização.

A despeito do avanço ofertado pela Política Nacional, as gestões municipais, ou seja, as prefeituras não possuem em parte ou em sua totalidade quadro de funcionários apto e disponível para receber, compreender e desenvolver as ações de elaboração e implantação das Políticas Municipais. Agregado a este importuno, o próprio modelo de gestão dos serviços por vezes é desorganizado e há a comentada confusão institucional entre os entes responsáveis pela titularidade, prestação e regulação. Por outro lado, potencializando-se esta gestão, melhorias são diretamente agregadas à população, pois se reduz a improvisação e ações emergenciais, substituindo-as por ações preconcebidas de curto prazo para problemas imediatos e de médio a longo, para encaminhamento futuro do setor (LISBOA, HELLER E SILVEIRA, 2013).Alday (2000) cita que o planejamento é um instrumento estratégico que, por meio de medidas antecipadas e positivas, propõem formas de solução de ameaças e otimiza oportunidades existentes. E complementa dizendo que as mudanças geradas pela reprogramação atingem os cunhos econômico, social, tecnológico e político.

A inexistência de equipe especializada e as debilidades na capacidade de gerenciamentos existentes em todas as esferas - Federal, Estadual e Municipal - fazem com que poucos municípios possuam uma gestão adequada dos serviços de saneamento e igualmente da busca pela sustentabilidade destes na aplicação de recursos técnicos, econômicos e financeiros. Tal incapacidade advém do modelo político implantado no Brasil e não resulta totalmente de indolência, contudo essa inabilidade impede que os Planos de Saneamento sejam integrais conforme requisitos legais, sejam eles elaborados pelas equipes municipais ou por consultorias contratadas para apoio.

A Lei $n^{\circ}$. 11.445/07 apresenta o conteúdo mínimo que os Planos devem possuir e há desdobramentos desta complementando e apoiando os municípios para o pleno atendimento da legislação, como o caso do Termo de Referência para elaboração de PMSB da Fundação Nacional de Saúde (Funasa) que define procedimentos de cooperação técnica e financeira e a Cartilha de Saneamento do Instituto Trata Brasil. No entanto, o cumprimento de todas as fases e etapas de elaboração para instituição de um planejamento completo não é seguido, fato que pode ser comprovado na observação dos planos existentes, tanto tecnicamente quando referente a qualidade da participação social implementada.

Abordando o estado da arte destes planejamentos municipais, o Brasil revela ter de 45 e $48 \%$ do total de municípios brasileiros com PMSB elaborados ou em elaboração segundo - Panorama Preliminar do Relatório elaborado pelo Ministério das Cidades (2007) com fontes de dados secundários consultados. Esta informação é no tocante quantitativo, de possuir ou não, e seria de grande valia a complementação qualitativa do panorama quanto ao conteúdo mínimo elaborado e a participação social. A região oeste do Paraná, alvo deste artigo, possui 52 municípios, todos eles com PMSB elaborados ou em fase de elaboração. Contudo, a partir da análise dos Planos constatou-se que apenas $17 \%$ apresentou a formação da Comissão, 13\% deles atenderam os preceitos da participação popular e ainda um representativo desatendimento nas ações de diagnóstico, prognósticos e ações, principalmente nos eixos drenagem urbana e resíduos sólidos.

Os estudos que embasam essas informações foram realizados no primeiro trimestre de 2015, a partir da análise de cada um dos planos municipais de saneamento da Região Oeste do Paraná. Destaca-se que o referencial para tais análises foram os requisitos da Política Nacional. Exposto na 
Tabela 1, é ainda ponto de observação que esta região possui $77 \%$ de seus municípios com população inferior 20 mil habitantes, possibilitando uma relação entre a incapacidade técnica das prefeituras e a baixa qualidade dos Planos.

Tabela 1.Faixas populacionais dos municípios do oeste do Paraná/PR

\begin{tabular}{l|c|c}
\hline Faixas populacionais & Municípios & $\%$ \\
\hline $\mathrm{Hab}<20.000$ & 42 & 77 \\
\hline $20.000<\mathrm{Hab}<50.000$ & 9 & 17 \\
\hline $\mathrm{Hab}>50.000$ & 3 & 6 \\
\hline
\end{tabular}

A proposta de apoio técnico abordada então por este artigo, de execução da Fundação Parque Tecnológico Itaipu - Brasil (FPTI-BR) em parceria com a Itaipu Binacional e amparada pela legislação e manuais de órgãos oficiais, trata de uma alternativa de elaboração e revisão dos planejamentos municipais objetivando 0 atendimento ao disposto em lei como conteúdo mínimo, priorizando as ações de mobilização social, o empoderamento técnico quanto ao saneamento, a conscientização e responsabilização das gestões locais e o diálogo sobre saneamento básico.

Assim, objetiva-se com este artigo apresentar a metodologia de trabalho da Fundação Parque Tecnológico Itaipu e ItaipuBinacional de apoio técnico e mobilização de prefeituras para elaboração ou revisão e implementação de Planos Municipais de Saneamento Básico, exemplificando com o caso de Pato Bragado/PR.

\section{DESENVOLVIMENTO}

Pelo caráter expositivo deste artigo, apresenta-se neste item os principais normativos de fundamentação dos PMSB e a metodologia de trabalho adaptada e aplicada.

\subsection{Projeto Saneamento Ambiental}

O Projeto Saneamento Ambiental (PSA), integrante do Programa Desenvolvimento
Econômico e Social Sustentável da Região Oeste do Paraná que faz parte do portfólio da Fundação Parque Tecnológico Itaipu Brasil (FPTI-BR), objetiva o avanço do diálogo sobre o saneamento básico em sua área de atuação com perspectiva de estender e prospectar ações voltadas ao avanço do setor, incluindo a mobilização social da população e das prefeituras. Para tanto, o Projeto oferta às instituições responsáveis apoio técnico e financeiro para elaboração ou revisão de Planos Municipais de Saneamento Básico por serem o mais recente e quiçá transformador instrumento que confere força ao tema e novamente 0 diálogo e trabalho pró saneamento básico, conquanto baseado agora em diretrizes sólidas da Lei Federal $n^{\circ}$. 11.445/2007.

Iniciado em 2013, o Projeto é fruto de uma parceria entre a FPTI-BR, a hidrelétrica Itaipu Binacional e o Banco Nacional de Desenvolvimento Econômico e Social (BNDES) que propiciam apoio de equipe técnica, apoio administrativo e ainda financeiro para municípios estabelecerem ou replanejarem seus serviços de saneamento. Este suporte envolve as diversas fases do processo, iniciando pela pactuação de um instrumento jurídico entre as partes, a formação de um Comitê Gestor das ações e explicação das fases e etapas do PMSB, a contratação de uma consultoria especializada a fim de potencializar o trabalho de campo e ainda fortalecer as soluções técnicas, engajamento da equipe municipal no desenvolvimento e recapitulação da responsabilidade pelo planejamento, discussão e mobilização com população de forma ampla em suas diversas classes, entre outros pontos que encaminham a elaboração à concepção da Política Nacional de Saneamento Básico.

\subsection{Diretrizes de Trabalho}

Para que municípios brasileiros desenvolvam inteiramente seus planejamentos municipais em saneamento básico, seja quanto a composição técnica dos relatórios ou ainda quanto ao processo de comunicação e mobilização social, diretrizes foram estabelecidas por instituições e órgãos envolvidos com o tema. São apresentados e comentados nesta subseção os principais documentos norteadores que objetivam, de 
maneira específica, auxiliar e fornecer recomendações e diretrizes para a elaboração dos PMSB.

A Lei de Saneamento procedeu-se de uma articulação legal e financeira iniciada pela esfera federal para que o Brasil alcance metas de atendimento mínimo da qualidade da água e saúde pública, visando então desenvolver este eixo e aplicá-lo a todo território nacional. Para tanto, foram instituídas legislações que regem os setores afins as causas, sendo então a Lei $\mathrm{n}^{\circ}$. 11.445 de 2007 que apresenta instruções nacionais para o saneamento básico coerente com as múltiplas realidades sociais, econômicas e ambientais a fim de proporcionar o alcance a toda extensão e esferas no Brasil.

A Política de Saneamento apresenta moldes de organização institucional dos serviços; estabelece o saneamento básico como objeto de planejamento integrado de elaboração do ente federado, passível de apoio de instituições e prestadores dos serviços; eleva o diálogo sobre regulação e fiscalização e ainda regras para o relacionamento entre titulares e prestadores de serviços, sempre por meio de contratos; e com destaque fixa as diretrizes básicas para a cobrança pela prestação dos serviços de saneamento básico. Desta forma, os Planos Municipais são o caminho para diálogo e promoção das metas federais de saúde pública, tendo o conteúdo descrito no artigo 19 da referida Lei:

O plano, que poderá ser específico para cada serviço, o qual abrangerá, no mínimo: diagnóstico da situação e de seus impactos nas condições de vida, utilizando sistema de indicadores sanitários, epidemiológicos, ambientais e socioeconômicos, apontando as causas das deficiências detectadas; objetivos e metas de curto, médio e longo prazo para a universalização, admitidas soluções graduais e progressivas, observando a compatibilidade com os demais planos setoriais; Programas, projetos e ações necessárias para atingir os objetivos e as metas, de modo compatível com os respectivos planos plurianuais e com outros planos governamentais correlatos, identificando possíveis fontes de financiamento; ações para emergências e contingências; mecanismos e procedimentos para a avaliação sistemática da eficiência e eficácia das ações programadas. (BRASIL, 2007).
Observa-se desta citação que há então um arcabouço técnico básico que sustenta o planejamento: diagnóstico, prognóstico, ações e monitoramento. Não obstante, a Lei toma a questão do controle social em todas as fases da concepção e implantação do PMSB, significando-o como o conjunto de mecanismos e procedimentos que garantem à sociedade informações, representações técnicas e participações nos processos de formulação de políticas, de planejamento e de avaliações relacionadas aos serviços públicos de saneamento básico (BRASIL, 2007). Portanto, na metodologia dos trabalhos deve-se garantir ações de mobilização social para assegurar tal participação.

Seguindo tais preceitos, a Fundação Nacional de Saúde (Funasa) expediu um Termo de Referência que subsidia os municípios de todo território nacional com informações e orientações, propiciando a vivência do planejamento municipal e salientando a metodologia participativa. Este caderno apresenta onze etapas estipuladas para elaboração de planos municipais, conforme Quadro 1, evidenciando com etapas específicas a composição de comitê e a participação social.

Quadro 1. Etapas de elaboração de PMSB

\section{Etapa Elaboração de Plano Municipal de Saneamento Básico}

\begin{tabular}{cl}
\hline $\mathbf{1}$ & Definição dos membros dos comitês \\
\hline $\mathbf{2}$ & Plano de mobilização social \\
\hline $\mathbf{3}$ & $\begin{array}{l}\text { Relatório do diagnóstico técnico- } \\
\text { participativo social }\end{array}$ \\
\hline $\mathbf{4}$ & $\begin{array}{l}\text { Relatório da prospectiva e } \\
\text { planejamento estratégico }\end{array}$ \\
\hline $\mathbf{5}$ & $\begin{array}{l}\text { Relatório dos programas, projetos e } \\
\text { ações }\end{array}$ \\
\hline $\mathbf{6}$ & Plano de execução \\
\hline $\mathbf{7}$ & $\begin{array}{l}\text { Minuta de projeto de lei do Plano } \\
\text { Municipal de Saneamento }\end{array}$ \\
\hline $\mathbf{8}$ & $\begin{array}{l}\text { Relatório sobre os indicadores de } \\
\text { desempenho do Plano Municipal de }\end{array}$ \\
\hline $\mathbf{9}$ & Saneamento Básico \\
\hline
\end{tabular}




\begin{tabular}{cl}
\hline & tomada de decisão \\
\hline 10 & $\begin{array}{l}\text { Relatório mensal simplificado do } \\
\text { andamento das atividades }\end{array}$ \\
\hline 11 & $\begin{array}{l}\text { Relatório final do Plano Municipal de } \\
\text { Saneamento Básico }\end{array}$
\end{tabular}

Fonte: Termo de Referência para elaboração de PMSB (Funasa, 2012).

\begin{abstract}
Destaca-se ainda deste orientativo algumas premissas indicadas como o planejamento integrado dos 4 eixos do saneamento e abrangência das áreas urbanas e rurais, compatibilidade com políticas e planos já instituídos, planejamento para 20 anos em metas de curto, médio e longo prazo, capacitação dos recursos humanos, desenvolvimento sustentável dos sistemas, a questão da revisão do PMSB a cada 4 anos e a integração com a Lei $n .-0$ 12.305/2010. A descrição de cada etapa de elaboração e produtos respectivos, as responsabilidades e funções e a equipe multidisciplinar necessária são descritos também no Termo de Referência da Funasa.
\end{abstract}

Verifica-se também as diretrizes da Secretaria Nacional de Saneamento Ambiental (SNSA) e do Ministério das Cidades que orientam o apoio aos municípios na condução dos PMSB. A SNSA/MCidades indica em seu relatório do Panorama dos Planos Municipais de Saneamento Básico no Brasil que o processo de elaboração, implantação, aprovação e monitoramento sejam:

- Um pacto social capaz de contribuir para reverter às desigualdades sociais por meio da universalização do acesso aos serviços e para sensibilizar a população sobre a relevância da política e da gestão dos serviços de saneamento básico para 0 desenvolvimento do município;

- Oportunidade de inserção do saneamento básico na agenda do município e envolvimento social para cooperação e compreensão da responsabilidade compartilhada;

- Instrumento municipal de programas e ações de saneamento básico com observância na previsão orçamentária e na execução financeira;
- Produto de implementação das macrodiretrizes e estratégias do Plano Nacional de Saneamento Básico (Plansab);

- Condição para pleitear recursos junto à União, organismos internacionais e construir parcerias com empresas privadas sediadas no município;

- Referência para o exercício das funções de regulação e fiscalização do saneamento no município e normativo dos contratos de prestação dos serviços;

- Instrumento para fortalecer e qualificar a participação popular e o controle social, de maneira a influenciar o processo decisório sobre as prioridades de investimentos e de ações no território.

Ao interpretar então 0 que as legislações e tais orientações, infere-se que as metas pelas quais os PMSB traçarão caminhos de atendimento visam a universalização do acesso ao serviço de saneamento básico integrando ações de segurança, qualidade e regularidade desse a fim da promoção da saúde pública e proteção ao meio ambiente. Deduz-se ainda que devem ser analisadas as particularidades de cenários e adoção de tecnologias adequadas para soluções gradualmente progressivas. Quanto a sustentabilidade, almeja-se a gestão com transparência de informações e com sustentabilidade econômica, não obstante da capacidade de pagamento dos usuários.

Ademais, são incorporadas outras legislações ligadas ao setor e ao planejamento municipal. A seguir, apresenta-se a lista de objetos normativos utilizados nestes trabalhos.

- Resolução ConCidades n. 62/08 Plano Nacional de Saneamento Básico (PLANSAB);

- Lei $\mathrm{n}^{\circ}$. 10.257/01 - Estatuto das Cidades;

- Lei $n^{\circ}$. 12.305/10 e Decreto $n^{\circ}$. 7.404/10 - Política Nacional de Resíduos Sólidos;

- Lei Estadual n. 12.493/99 - Gestão dos resíduos sólidos no Estado do Paraná;

- Lei $n^{\circ}$. 8.987/95 - Lei de Concessão e Permissão de serviços públicos;

- Lei n. 9.705/99 - Educação Ambiental;

PERIÓDICO TCHÊ QUÍMICA • www.periodico.tchequimica.com • Vol. 15 N. 29. •ISSN 1806-0374 (impresso) • ISSN 1806-9827 (CD-ROM) • ISSN 2179-0302 (meio eletrônico) 
- Resolução CONAMA n. 307/02 Gestão dos resíduos da construção civil;

- Resolução CONAMA n. 283/01 Gestão dos resíduos dos serviços de saúde;

- Dispositivos municipais: Lei Orgânica, Plano Diretor e planejamentos anteriores em Saneamento Básico e Resíduos Sólidos em casos de revisão.

\subsection{Metodologia de Desenvolvimento do PMSB}

O trabalho de apoio aos municípios baseia-se em um protocolo que determina ações prévias, de execução e posteriores a instituição do PMSB. Além do aporte financeiro a equipe técnica do Projeto Saneamento Ambiental (PSA) permanentemente reforça concepções de titularidade, relevância de priorização do tema, engajamento da equipe municipal de técnicos a gestores, conscientização da indispensabilidade da instância social no processo, além de toda legalidade do processo de parceria e execução, aliadas às questões de cunho técnico.

Além desta convenção, utiliza-se na execução dos trabalhos um Termo de Referência padrão, documento que rege o processo de mobilização e desenvolvimento dos Planos e que constantemente é atualizado e aperfeiçoado. Elaborado conforme preceitos da Política Nacional de Saneamento Básico e documentos tais como os emitidos pela Funasa, este Termo norteia de forma sistêmica o desenvolvimento dos planejamentos apoiados pelo PSA, demandando de cada ente envolvido conforme suas incumbências.

A proposta de apoio aos PMSB é composta por três fases divididas em sete etapas conforme apresentado no Quadro 2 e os produtos gerados correspondem a relatórios contendo a descrição de cada uma das etapas, sendo tais correlatas e consecutivas.
Quadro 2. Fases e Etapas do Processo de revisão do PMSB

FASE I - Planejamento do Processo

Etapa 1 - Coordenação, Participação Social e comunicação

\section{FASE II - Elaboração/revisão do PMSB}

Etapa 2 - Diagnóstico dos sistemas de saneamento básico

Etapa 3 - Prognósticos e Diretrizes, Objetivos e Metas

Etapa 4 - Programas, projetos e ações

Etapa 5 - Ações de emergência e contingência

Etapa 6 - Mecanismos e procedimentos para a avaliação das ações

\section{FASE III - Aprovação do PMSB}

Etapa 7 - Aprovação do PMSB

Fonte: Projeto Saneamento Ambiental, 2017.

\section{Etapa 1 - Mobilização Social}

A mobilização a fim da participação popular na elaboração dos planos municipais se estabelece transversalmente em todas as etapas de desenvolvimento, visto: a carência por seu caráter democrático e participativo, envolvendo a população na discussão das potencialidades e sensibilizando-a para a responsabilidade coletiva; o esclarecimento da importância de investimentos; e o incentivo aos gestores e técnicos municipais para o fomento das ações. Os meios de comunicação e divulgação devem ser diversos e analisados no contexto do município, como o folheto apresentado na Figura 1 de convocação da população para a Audiência Pública em Pato Bragado/PR. 


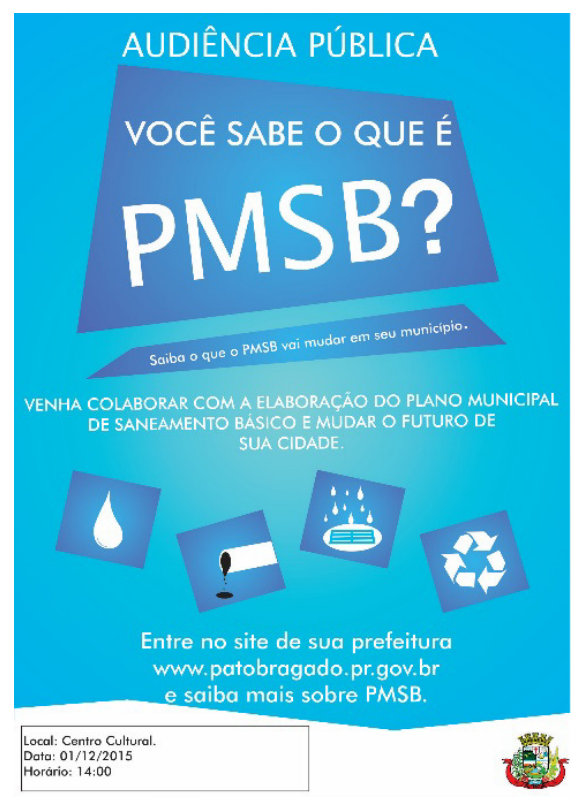

Figura 1.Folheto de comunicação e mobilização social do PMSB.

\section{Etapa 2 - Diagnóstico Técnico-Participativo}

Fase de estudos e caracterização dos aspectos socioeconômicos, culturais, ambientais e de infraestrutura do município, além do descritivo e análise dos sistemas de abastecimento de água, esgotamento sanitário, drenagem urbana e manejo de resíduos sólidos e limpeza urbana, a partir de dados primários e secundários. Esta, pode-se afirmar, é a fase de maior relevância por ser base orientadora do PMSB.

\section{Etapa 3 - Prognósticos e metas}

O prognóstico prevê alternativas para tal universalização no município por meio de cenários prospectivos em diferentes horizontes de tempo, assegurado pelo diagnóstico. Esta etapa inclui o planejamento da organização ou adequação das estruturas municipais para o planejamento, a prestação de serviço, a regulação, a fiscalização e o controle social dos serviços. E a partir destes cenários que são propostos programas, projetos e ações que materializam estas perspectivas.

Etapa 4 - Programas, projetos e ações

Fase de proposição de planejamentos e ações integradoras a fim de impulsionar soluções necessárias para alcance dos objetivos e metas considerando viabilidade técnica e econômica e possibilidades e ameaças do município. Nesta etapa, delimitase o caminho pelo qual a gestão municipal deverá conduzir 0 desenvolvimento dos serviços, com custos, prazos, relevância e fontes de recursos econômicos.

\section{Etapa 5 - Ações para emergência e contingências}

Identificação de possíveis formas de prevenção de situações de risco ou desastre, planos de racionamento e atendimento a demandas temporárias. Fase importante que norteia ações em momento de crise ou emergência previamente aos acontecimentos, coincidindo com o cerne de antecipação do Planejamento.

\section{Etapa 6 - Mecanismos de avaliação}

Descrição da metodologia e procedimentos de avaliação, por meio de indicadores de eficiência e eficácia de todos os programas, projetos e ações previstas nas etapas anteriores, definindo a instância responsável pela regulação ou fiscalização do PMSB, a periodicidade de divulgação do monitoramento e o detalhamento do processo de revisão do plano. Por meio destes indicadores, verifica-se o cumprimento das ações para evolução dos sistemas de saneamento, tornando-se além de um mensurador, instrumento de incentivo ao alcance das metas.

\section{Etapa 7 - Aprovação do PMSB}

Por meio de uma Audiência Pública com participação da comunidade, o PMSB tem suas etapas concluídas e aprovadas pelas instâncias sociais presentes. Ademais, reforça-se junto à municipalidade a necessidade de que o Plano seja encaminhado à respectiva Câmara de Vereadores a fim de tornar-se instrumento de uma Política Municipal de Saneamento Básico, instituída por esta instância via lei ou decreto. Este ato pactua a finalização do planejamento e fortalece seus instrumentos e consolidação 
intergestões, além de reforçar com o administrador público a incumbência de sua execução, conforme exposto na Figura 2 a seguir onde o prefeito do município recebe as versões completas do PMSB.

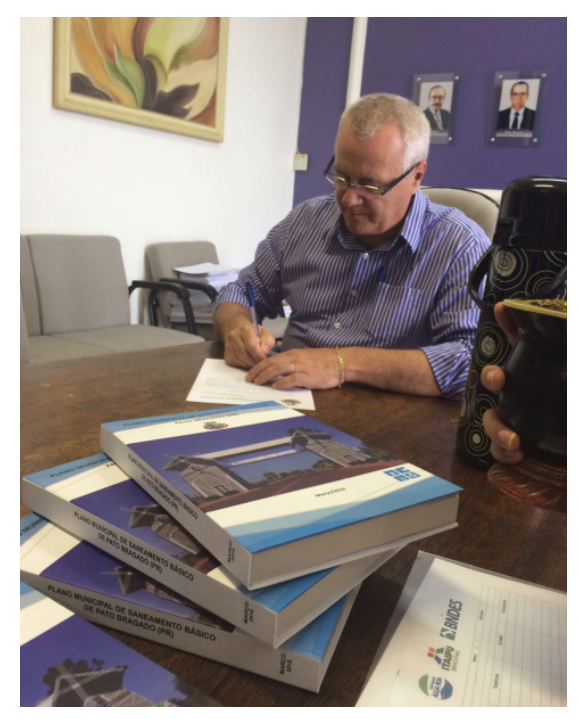

Figura 2. Aprovação da versão final do $P M S B$ pela prefeitura.

\section{RESULTADOS E DISCUSSÃO}

Os resultados obtidos a partir da aplicação da metodologia de trabalho do Projeto Saneamento Ambiental estão demonstrados no caso do município de Pato Bragado - Paraná descrito a seguir e comentado segundo preceitos de elaboração de PMSB descritos este artigo.

\subsection{Plano Municipal de Saneamento Básico de Pato Bragado/PR}

Abrangido na região oeste do Paraná, o município de Pato Bragado, localizado à margem do reservatório da usina Itaipu Binacional, possui 5.055 habitantes e área territorial de $135,29 \mathrm{~km}^{2}$, sendo70\% urbana conforme apresentado na Figura 3. Em parceria com o Projeto Saneamento Ambiental da FPTI-BR, o município elaborou seu PMSB de maio a dezembro de 2015 coordenado pelos Comitês de Coordenação e Técnico Executivo (Portaria Municipal n. $\stackrel{0}{189}$, de 29 de maio de
2015).

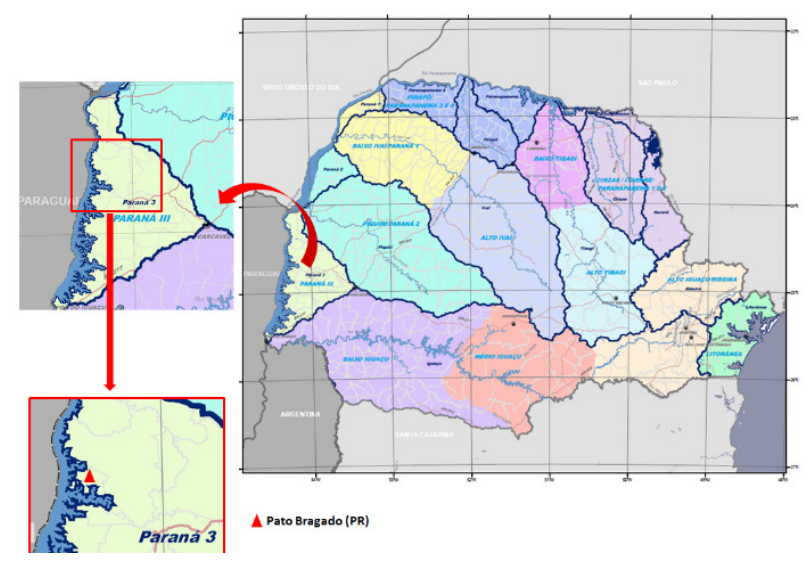

Figura 3. Localização do Municípios de Pato Bragado/Paraná - Brasil.

Após definição da comunicação da elaboração do Plano e de mobilização social descritos em relatório inicial da Etapa 1, 0 Comitê juntamente a equipe de apoio percorreu o município em suas áreas urbanas e rurais para diagnóstico, com obtenção de dados, informações e fotografias retratando 0 panorama dos sistemas de saneamento básico. Foram obtidos dados secundários de fontes oficiais e da prefeitura e ainda primários por meio da aplicação de questionários em uma amostragem de domicílios, empresas, instituições e também junto a associação e catadores de materiais recicláveis como exemplificado pela Figura 4.

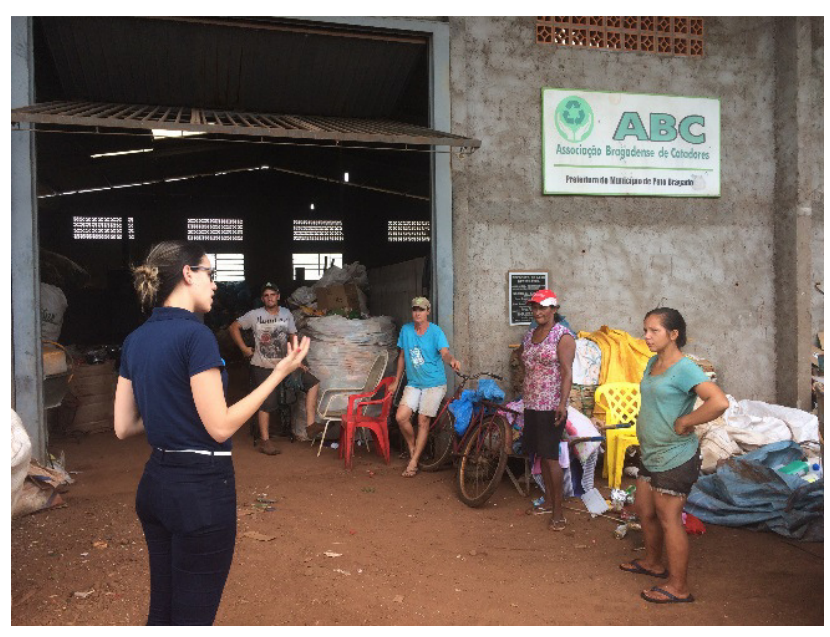

Figura 4.Mobilização social com a associação de catadores de materiais recicláveis. 
A Etapa 2 resultou então em um relatório com abordagem sistêmica, cruzando informações socioeconômicas, ambientais e institucionais, gerando a caracterização completa do município - histórico, divisão territorial, unidades hidrográficas, meio físico, aspectos econômicos, indicadores de saúde, estudo de projeção populacional - e o diagnóstico aprofundado da situação dos sistemas - atendimento, frequência e falhas, estrutura institucional, situação dos equipamentos, pesquisa pública, riscos e potencialidades.

Paralelamente ao início da Etapa 3, foi realizado no município uma pré-audiência para apresentação à população do Diagnóstico, permitindo aos munícipes uma clara análise situacional do sistema, tanto de atendimento quanto tarifário, aproximando-os da gestão. A construção dos cenários futuros e as ações necessidade para seus cumprimentos foram discutidas no âmbito do Comitê, como demonstrada em reunião retratada na Figura 5, e descritos em fichas contendo, para cada eixo do saneamento, o programa, o objetivo deste, a fundamentação que levou sua criação, o método de monitoramento desta, as metas em curto, médio e longo prazo e as descrições das ações, orçamento e fontes de recursos para cada uma dessas, totalizando 46 fichas desdobradas em diversas ações dispostas de cronograma físico-financeiro e atendendo a Etapa 4.

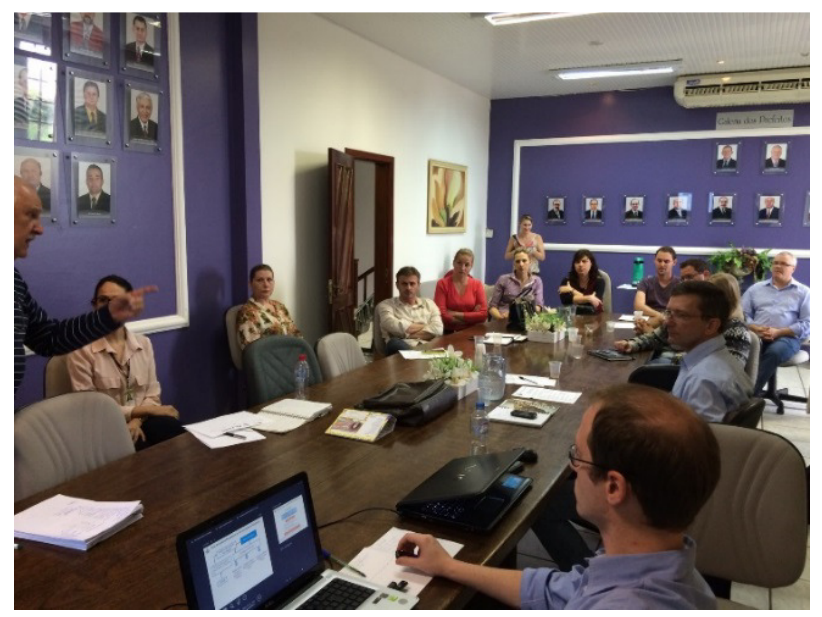

Figura 5. Reunião do comitê de coordenação e execução do PMSB.
Destaca-se aqui a discussão sobre o modelo institucional ocasionada no município onde apresenta-se no plano a descrição de cada modalidade - autarquia, concessão, departamento, gestão associada, etc. - com o intuito de subsidiar a definição do modelo de gestão do saneamento, considerando a dispersão interna da prefeitura nesta administração. Outros pontos discutidos com maior ênfase foram a questão tarifária e a sustentabilidade do sistema, a implantação do modelo coletivo de esgotamento sanitário e a regulação e fiscalização dos serviços.

A Etapa 5 foi trabalhada segundo um elenco de eventos e medidas emergenciais combinados conforme cada componente dos sistemas. Quanto aos mecanismos para avaliação da eficiência, efetividade e eficácia das ações, um conjunto de indicadores foi definido com base nos sistemas existentes e ações propostas resultando em um índice de qualidade, nos âmbitos: técnico, operacional e financeiro; qualidade de vida, saúde e recursos naturais; sanitários, epidemiológicos e socioeconômicos; salubridade ambiental; controle social; entre outros.

Após a junção dos relatórios das etapas e as discussões finaiselaborou-se o documento final do PMSBrepresentada pela Figura 6, um caderno síntese deste e uma intensa mobilização social no município para a Audiência Pública onde aprovou-se 0 planejamento para os próximos 20 anos. Destaca-se o período de 15 dias anteriores a esta ação onde foi realizada a consulta pública manifestada via Edital de Chamamento. Então, em maio de 2016, a Lei Municipal n. -1.531 instaurou a Política Municipal de Saneamento Básico de Pato Bragado, instrumento que delega dever de cumprimento ao PMSB transcendentemente gestões. 


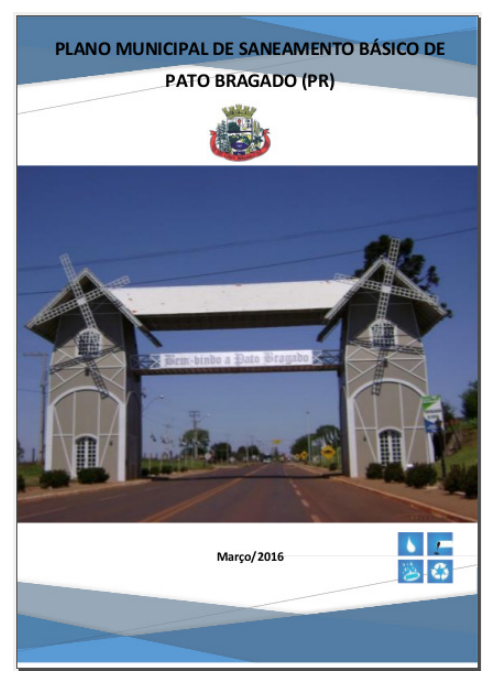

Figura 6. Relatório final do PMSB de Pato Bragado/PR (capa).

Perfazendo este processo, conclui-se que o PMSB de Pato Bragado foi elaborado seguindo os preceitos das legislações e, conforme objetivos do Projeto Saneamento Ambiental (PSA), houve o engajamento da prefeitura na proposta de discussão e priorização do tema. A fase subsequente devida é a implantação do planejamento e, para tal, o PSA mantém continuo apoio para mobilização da gestão local com propósito de efetivação de ações.

\section{CONCLUSÕES}

Nota-se que as iniciativas de elaboração de Planos têm progredido em número e qualidade nos municípios brasileiros, por conscientização de sua importância e por ser condicionante ao recebimento de recursos da União. Acredita-se que, frente a esta disseminação ocorrente entre os municípios, a qualidade do Plano e da discussão social sobre saneamento tenda ao aprimoramento de sua concepção, desenvolvimento e utilização. Sendo assim, é possível que esta conscientização incentive ainda, após seus vencimentos, a revisão destes Planos que também coincidirão em seu aperfeiçoamento.

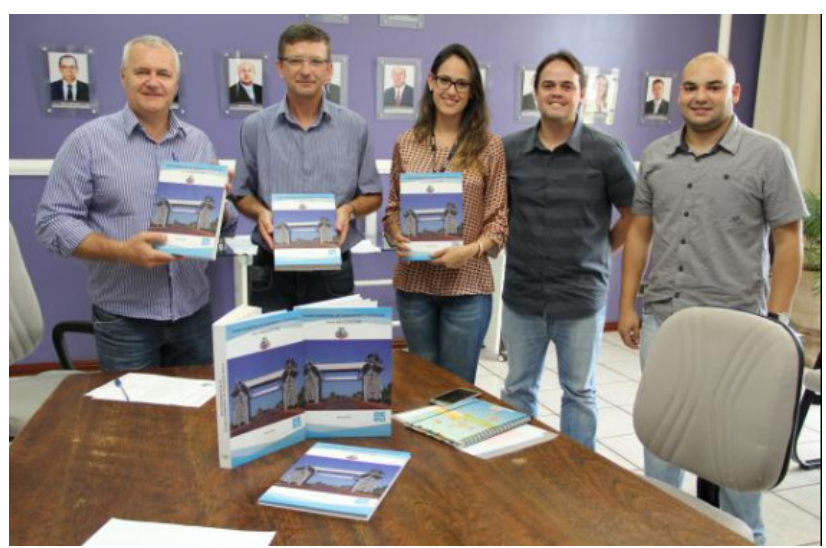

Figura 7. Entrega final do PMSB a prefeitura.

Como consideração dos autores, crêse que esta discussão dos PMSB e dos serviços devem ser intensificados em debates sobre a necessidade de compreensão da premência e benefícios do saneamento básico pela gestão pública por meio de capacitação ou outras formas, como vem executando 0 Ministério das Cidades, FUNASA, etc. O engajamento da administração pública, como demonstrado pela Figura 7, e a participação social são premissas para um crescimento evolutivo em quantidade e qualidade dos PMSB. Como comentado por Philippi (1997), uma solução para consubstanciar 0 saneamento no âmbito municipal seria inicialmente pela incorporação desse por secretarias ou conselhos, além da vigilância sanitária e ambiental, para que promovessem então programas e projetos efetivos. Temas intrínsecos como regulação, fiscalização e regionalização ou serviços consorciados devem entrar na pauta de tais discussões para propósito do avanço do saneamento básico no Brasil.

\section{REFERÊNCIAS}

1. ALDAY, Hernan E. Contreras. O planejamento estratégico dentro do conceito de administração estratégica. Revista FAE, Curitiba, v. 3, n. 2, p. 9-16, 2000.

2. AMOP. Associação dos Municípios do Oeste do Paraná. Disponível em: $<$ http://www.amop.org.br/>. Acessado em: 07 ago. 2015.

3. BRAGA, Roberto. Plano Diretor Municipal: três questões para discussão. 
Caderno do Departamento de Planejamento, Presidente Prudente, v. 1, n. 1, p. 15-20, 1995.

4. BRASIL. Decreto no 7.217 de 21 de junho de 2010, que regulamenta a Lei $\mathrm{n}^{\circ}$. 11.445, de 5 de janeiro de 2007 e dá outras providências. DOU, Brasília, $2017 . \quad$ Disponível em: <http://www.planalto.gov.br/ccivil_03/_at 02007-2010/2010/decreto/d7217.htm>.

Acesso em: 17 abr. 2015.

$5 . \quad$ Lei no 11.445 de 5 de janeiro de

2007. Estabelece diretrizes nacionais

para o saneamento básico. DOU, Brasília, 2007b. Disponível em: <http://www.planalto.gov.br/ccivil_03/_at o2007-2010/2007/lei//11445.htm>.

Acesso em: 15 jun. 2017.

6. de 2010. Institui a Política Nacional de Resíduos Sólidos e dá outras providências. DOU, Brasília, 2010c. Disponível em: <http://www.planalto.gov.br/ccivil_03/_at o2007-2010/2010/lei//12305.htm>.

Acesso em: 15 jun. 2017.

7. Panorama dos Planos Municipais de Saneamento Básico no Brasil. Ministério das Cidades. Edição: Janeiro de 2017. Brasília, 2017.

$8 . \quad$ Política e Plano Municipal de Saneamento Ambiental: experiências e recomendações. Brasília: Ministério das Cidades/OPAS. 2005.

9. DEMOLINER, K.S. Água e saneamento básico: regimes jurídicos e marcos regulatórios no ordenamento brasileiro. Porto Alegre, Livraria do Advogado, 2008, $220 \mathrm{p}$.

10. ESCODA, Maria do Socorro Quirino. Avaliação de efetividade de ações de saneamento: análise de gestão. Ciência e Saúde Coletiva, v. 10, n. 2, p. 493-497, 2005.

11. FUNASA, Fundação Nacional de Saúde. Termo de Referência para a elaboração do Plano Municipal de Saneamento Básico. Brasília, 2012. 68 p.

12. HELLER, Léo. Relação entre saúde e saneamento na perspectiva do desenvolvimento. Ciência e Saúde Coletiva, v. 3, n. 2, p. 73-84, 1998.

13. IBGE. Instituto Brasileiro de Geografia e
Estatística. Pesquisa nacional de saneamento básico (2008). Rio de Janeiro, IBGE, 219 p. 2010.

14. IBGE. Instituto Brasileiro de Geografia e Estatística. Pesquisa nacional de saneamento básico (2008). Rio de Janeiro, IBGE, 219 p. 2010.

15. JUNIOR, Alceu de Castro Galvão; SOBRINHO, Geraldo Basilio; SAMPAIO, Camila Cassundé. A Informação no Contexto dos Planos de Saneamento Básico. Fortaleza: Expressão Gráfica Editora, 2010.285p.

16. LAHOZ, Rodrigo Augusto Lazzari; DUARTE, Francisco Carlos. Saneamento básico e direito à saúde: considerações a partir do princípio da universalização dos serviços públicos. RECHTD-Revista de Estudos Constitucionais, Hermenêutica e Teoria do Direito, v. 7, n. 1, p. 62-69, 2015.

17. LEONETI, Alexandre Bevilacqua; DO PRADO, Eliana Leão; DE OLIVEIRA, Sonia Valle Walter Borges. Saneamento básico no Brasil: considerações sobre investimentos e sustentabilidade para o século XXI. Revista de Administração Pública, v. 45, n. 2, p. 331-348, 2011.

18. LISBOA, Severina Sarah; HELLER, Léo; SILVEIRA, Rogério Braga. Desafios do planejamento municipal de saneamento básico em municípios de pequeno porte: a percepção dos gestores. Engenharia Sanitária e Ambiental, v. 18, n. 4, p. 341-348, 2013.

19. PHILIPPI, Luiz Sérgio. V-002: Saneamento descentralizado como instrumento para o desenvolvimento sustentável. IN: Anais do IX SILUBESA - Simpósio Luso-Brasileiro de Engenharia Sanitária e Ambiental. Bahia: ABES, p. 1833 - 1841. 1997.

20. PMSB/PB. Plano Municipal de Saneamento Básico de Pato Bragado/PR. 2016. Disponível em: $<$ http://www.patobragado.pr.gov.br/artig o/222/Plano-Municipal-de-SaneamentoBasico/176>. Acesso em: 20 jun. 2017.

21. QUINTAS, José Silva. Introdução à gestão ambiental pública. IBAMA, 2005.

22. SERILO, Daviany Farinelli; VALENTINI, Carla Maria Abido; DE FARIA, Rozilaine Aparecida Pelegrine Gomes. 
saneamento básico de Cuiabá-MT na memória dos idosos em um bairro histórico da capital. Biodiversidade, v. 13, n. 1, 2014.

PERIÓDICO TCHÊ QUÍMICA • www.periodico.tchequimica.com • Vol. 15 N. 29. •ISSN 1806-0374 (impresso) • ISSN 1806-9827 (CD-ROM) • ISSN 2179-0302 (meio eletrônico) (C) 2018. Porto Alegre, RS. Brasil

The Periódico Tchê Química (ISSN: 1806-0374; 2179-0302) is an open-access journal since 2004. Journal DOI: 10.52571/PTQ. http://www.tchequimica.com. This text was introduced in this file in 2021 for compliance reasons.

OPEN ACCESS. This article is licensed under a Creative Commons Attribution 4.0 (CC BY 4.0) International License, which permits use, sharing, adaptation, distribution, and reproduction in any medium or format, as long as article 's Creative Commons license unless indicated and the source, provide a link to the Creative Commons license, and indicate if changes were made. The images or other third-party material in this article are included in the or exceeds the permitted use, you will need to obtain permission directly from the copyright holder. To view a copy of this license, visit http://creativecommons.org/licenses/by/4.0/. 